\section{Parceria público-privada na gestão hospitalar no Sistema Único de Saúde da Bahia, Brasil}

\author{
Public-private partnerships in hospital administration \\ in the Brazilian Unified National Health System \\ in Bahia State, Brazil
}

\section{Colaboración público-privada en la gestión hospitalaria en el Sistema Único de Salud de Bahía, Brasil}

Laise Rezende de Andrade 1

Isabela Cardoso de Matos Pinto 1

\section{Resumo}

O processo de construção do Sistema Único de Saúde (SUS) tem sido, desde o início, espaço de disputa entre as forças políticas que defendem a ampliação da participação do setor privado na assistência e gestão dos serviços, e os defensores do fortalecimento da gestão pública. No contexto do subfinanciamento do SUS, associado às restrições impostas pela Lei de Responsabilidade Fiscal, novos modelos de gestão têm sido adotados, especialmente na área de gestão hospitalar, a exemplo da parceria público-privada (PPP). Considerando a relevância de investigar os processos de decisão relativos à adoção desses modelos pelas Secretarias Estaduais de Saúde, este trabalho tem por objetivo analisar os processos de tomada de decisão e incorporação desse modelo de gestão hospitalar no Estado da Bahia, Brasil, primeira concessão administrativa no setor de saúde do Brasil. Trata-se de um estudo de caso que tomou como referencial teórico a teoria do jogo social, elaborada por Carlos Matus, articulada ao modelo analítico do Ciclo de Políticas Públicas. Os dados foram produzidos a partir de pesquisa documental e entrevistas semiestruturadas com informantes-chave que participaram dos momentos de pré-decisão e decisão acerca do modelo PPP. O artigo apresenta o jogo politico em torno da escolha dessa alternativa entre outros modelos para gestão hospitalar, além de debater vantagens e desvantagens dos modelos segundo atores-chave entrevistados, e conclui que determinantes não apenas financeiros, mas também políticos e ideológicos marcaram o processo de decisão pelo modelo PPP na Bahia, que teve como fomentador e consultor o braço direito do Banco Mundial, a Corporação Financeira Internacional.

Parcerias Público-Privado; Administração Hospitalar; Política Pública; Sistema Único de Saúde

\author{
Correspondência \\ L. R. Andrade \\ Praça Dr. Jorge Calmon, casa 187, Salvador, BA \\ 40295-500, Brasil. \\ laiseandrade@hotmail.com \\ 1 Instituto de Saúde Coletiva, Universidade Federal da Bahia, \\ Salvador, Brasil.
}




\section{Introdução}

Os gestores do Sistema Único de Saúde (SUS) vêm enfrentando uma série de desafios para cumprir o dever do Estado, expresso na Constituição Federal de 1988, especialmente por conta do histórico subfinanciamento do SUS, que dificulta a garantia de uma saúde pública universal, integral e de qualidade 1. Esta limitação financeira refreia um conjunto de investimentos para a construção de novas unidades, compra de equipamentos e manutenção da infraestrutura, situação agravada pela Lei de Responsabilidade Fiscal 2, que impõe limites também à contratação de pessoal. Assim, a gestão do SUS vive sob tensão de interesses do grande capital, forjados, segundo Souza ${ }^{3}$, nas diretrizes (im)postas pelo Banco Mundial desde a década de 1990 e ecoadas pelos seus porta-vozes nacionais.

Atualmente, $54 \%$ do gasto em saúde é efetuado no setor privado, que atende apenas $25 \%$ da população, sendo que o SUS, responsável por atender cerca de $75 \%$ da população, conta com apenas $46 \%$ do total. No entanto, em recente relatório, o Banco Mundial sugere que o Brasil teria gasto excessivo com a saúde (9,3\% do PIB), sem assinalar que parcela desse recurso se destina aos estratos mais ricos da população 4 .

O referido relatório do Banco Mundial afirmou que a atenção hospitalar é ineficiente, com base em indicadores de produtividade, não considerando o conjunto de benefícios em relação ao acesso e à inclusão de pessoas oriundas dos estratos mais pobres da população. Segundo Campos 4, a racionalidade economicista, presente no relatório do Banco Mundial, não leva em conta o direito à saúde ou possíveis mudanças no modelo de gestão e de cuidado no espaço público, porquanto a inclusão social deve ser um dos indicadores de avaliação da efetividade da política e da prestação de serviço de saúde.

No que tange à atenção hospitalar, o Brasil contava, em 2018, com 6.687 hospitais (especializados, gerais e hospitais dia). O número total de leitos no Brasil era de 433.686, desses, 299.365 mil leitos SUS e 92.438 encontravam-se no Nordeste 5.

Para Mota 6, a capacidade instalada de leitos de UTI (unidades de terapia intensiva) nas regiões Norte e Nordeste pode ser considerada precária em relação ao restante do país. Enquanto a região Sudeste, em 2020, contava com 1,16 leitos UTI SUS por 10 mil habitantes e a Sul com 1,39, a Região Norte possuía 0,79 e a Nordeste, 0,87, sendo que a Bahia possuía 0,77 leitos UTI SUS. Segundo o autor, essa situação é agravada porque as populações dessas regiões têm maior dependência do SUS para serviços assistenciais especializados, por conta de suas condições socioeconômicas. A Bahia, por exemplo, possui 417 municípios, desses apenas 46 com população acima de 50 mil habitantes e somente 23 cidades têm leitos de UTI.

Além das desigualdades territoriais e de infraestrutura, a atenção hospitalar no SUS enfrenta grandes desafios de gestão relacionados à garantia de eficiência, ao controle de custos, à qualidade da atenção e segurança do paciente, à provisão de acesso a cuidados abrangentes e coordenação com a atenção básica. Diante disso, os gestores do SUS na Bahia têm adotado diferentes modelos de gestão de serviços, especificamente na gestão hospitalar, na busca por alternativas para promover mudanças na natureza jurídico-administrativa dos serviços públicos de saúde 7 .

$\mathrm{Na}$ Bahia, estado que conta com apenas 653 hospitais, dos quais 465 são classificados como hospitais gerais 5 , a grande maioria vinculada ao setor privado, o caminho adotado pelos gestores públicos para ampliação da oferta de atenção hospitalar no SUS tem sido a constituição de parcerias com o setor privado, inicialmente por meio de Organizações Sociais (OS) e, a partir de 2010, por meio de parcerias público-privadas (PPP), experiências que necessitam de investigação e avaliação 8 .

A revisão de literatura realizada entre 2016 e 2018 nas bases de dados BVS, MEDLINE, SciELO, Web of Science e LILACS, acerca da temática PPP na gestão hospitalar, destacou que apenas 29 artigos dos 170 encontrados tratavam especificamente da gestão hospitalar. Essa escassez da produção aponta para a relevância deste estudo, pois urge a ampliação da produção científica acerca dessa modalidade de gestão hospitalar que tem crescido no cenário nacional e mundial, como demonstram os estudos encontrados 9,10,11,12,13,14,15,16,17,18,19.

Nos artigos sobre a PPP na gestão hospitalar, foram mapeadas as seguintes abordagens sobre o tema: variedade de definições acerca do que é PPP; sua diversidade de arranjos; desafios na modelagem de projetos; qualidade e conteúdo dos contratos; compartilhamento de risco; regulação; eficiência do financiamento privado e performance da parceria; necessidade de avaliação da utilização 
do modelo; correlação das PPPs com a ideia de modernização, inovação e ampliação de acesso a serviços 9,10,11,12,13,14,15,16,17,18,19.

Destacam-se também os artigos relacionados ao papel dos stakeholders 17 (atores que têm interesse no problema e em sua solução) e os desafios das parcerias referentes à transparência, governança, governabilidade e gestão 12 .

Apenas dois desses estudos, um do Chile 10 e outro da Itália 18, mencionaram as razões da escolha do modelo PPP, sinalizando para a lacuna na literatura e necessidade de investigação científica que aprofunde a compreensão acerca da ampliação deste modelo no campo da saúde.

Assim, buscando responder à pergunta de por que e como a Secretaria de Saúde do Estado da Bahia (Sesab) adotou o modelo PPP na gestão hospitalar, este artigo tem como objetivo analisar os processos de tomada de decisão e adoção desse modelo de gestão em um hospital selecionado do SUS do Estado da Bahia (SUS-BA), o Hospital do Subúrbio.

\section{Estratégia teórico-metodológica}

Esse estudo se insere na linha de pesquisa de análise política em saúde e busca identificar e analisar a diversidade de interesses, eventualmente conflitantes, dos diversos atores envolvidos, direta e indiretamente, no processo de decisão política em torno da adoção (ou não) de determinado modelo de gestão das unidades de saúde, como é o caso dos hospitais.

Nessa perspectiva, definiu-se como "caso" 20 o processo de decisão em torno da adoção do modelo PPP para gestão do Hospital do Subúrbio, unidade vinculada à rede estadual do SUS-BA, buscando compreender o jogo de interesses entre os atores envolvidos e suas motivações para a escolha desse modelo na gestão hospitalar.

Para isso, foi construído um modelo analítico (Figura 1) que tomou como ponto de partida a revisão dos elementos da Teoria do Jogo Social de Carlos Matus 21 e do Ciclo da Política Pública de John Kingdon 22, de modo a referenciar a análise do "jogo" de interesses, envolvendo competição, conflito e cooperação no debate sobre os modelos de gestão hospitalar a serem adotados no SUS-BA em cada um dos "fluxos da política", quais sejam: (a) o fluxo dos problemas, no caso, a problemática da gestão dos hospitais públicos no estado, no contexto de restrição fiscal e orçamentária; (b) o fluxo das políticas, no caso, a busca de alternativas para a solução do problema, por parte dos atores participantes do processo decisório em função de seus interesses; e (c) o fluxo político propriamente dito, ou seja, o processo no qual as alternativas foram debatidas e negociadas, conduzindo à decisão final aprovada de adotar o modelo PPP para a gestão do Hospital do Subúrbio.

A análise de como o processo decisório se deu, no âmbito do SUS-BA, partiu da identificação do momento em que tal proposta foi incluída na agenda governamental, levando-se em conta a distinção feita por Kingdon 22 entre o momento da pré-decisão e o momento da decisão. Além disso, usou-se a tipologia proposta por este autor para mapear os participantes ativos no processo decisório, ou seja, os atores governamentais (representantes do executivo, legislativo e os servidores públicos) e os atores não governamentais (especialistas; grupos de interesse centrados em indústrias e negócios, categorias profissionais, grupos de interesse público e lobistas; mídia e opinião pública; acadêmicos e partidos políticos), incluindo-se atores invisíveis.

A produção de dados contemplou pesquisa documental, detalhada no Quadro 1. Incluiu decretos, leis, portarias, resoluções, editais, contratos e demais documentos disponíveis para consulta pública, além de acompanhamento de publicações nos sites da Sesab, Secretaria da Fazenda do Estado da Bahia (Sefaz) e outros relacionados ao negócio PPPs.

Também foram realizadas entrevistas semiestruturadas, com atores-chave, entre 2016 e 2019, selecionados a partir da leitura prévia dos documentos que apresentavam nomes dos representantes das instituições que participaram do processo de decisão e, também, utilizou-se a técnica 23 "Bola de Neve". Essa técnica assegurou heterogeneidade, ao permitir indicações de atores governamentais e não governamentais diversos, o que atendeu aos critérios de interesse da pesquisa.

Assim, os atores governamentais entrevistados foram os dirigentes da Sesab (4); Sefaz (1), onde está localizada a Secretaria Executiva do Programa de PPPs da Bahia; e da Procuradoria Geral do Estado - PGE (1). Os atores não governamentais entrevistados foram representantes do Conselho 


\section{Figura 1}

Modelo analítico do processo decisório em torno da adoção do modelo parceria público-privada (PPP) para gestão hospitalar no Sistema Único de Saúde (SUS) da Bahia, Brasil.

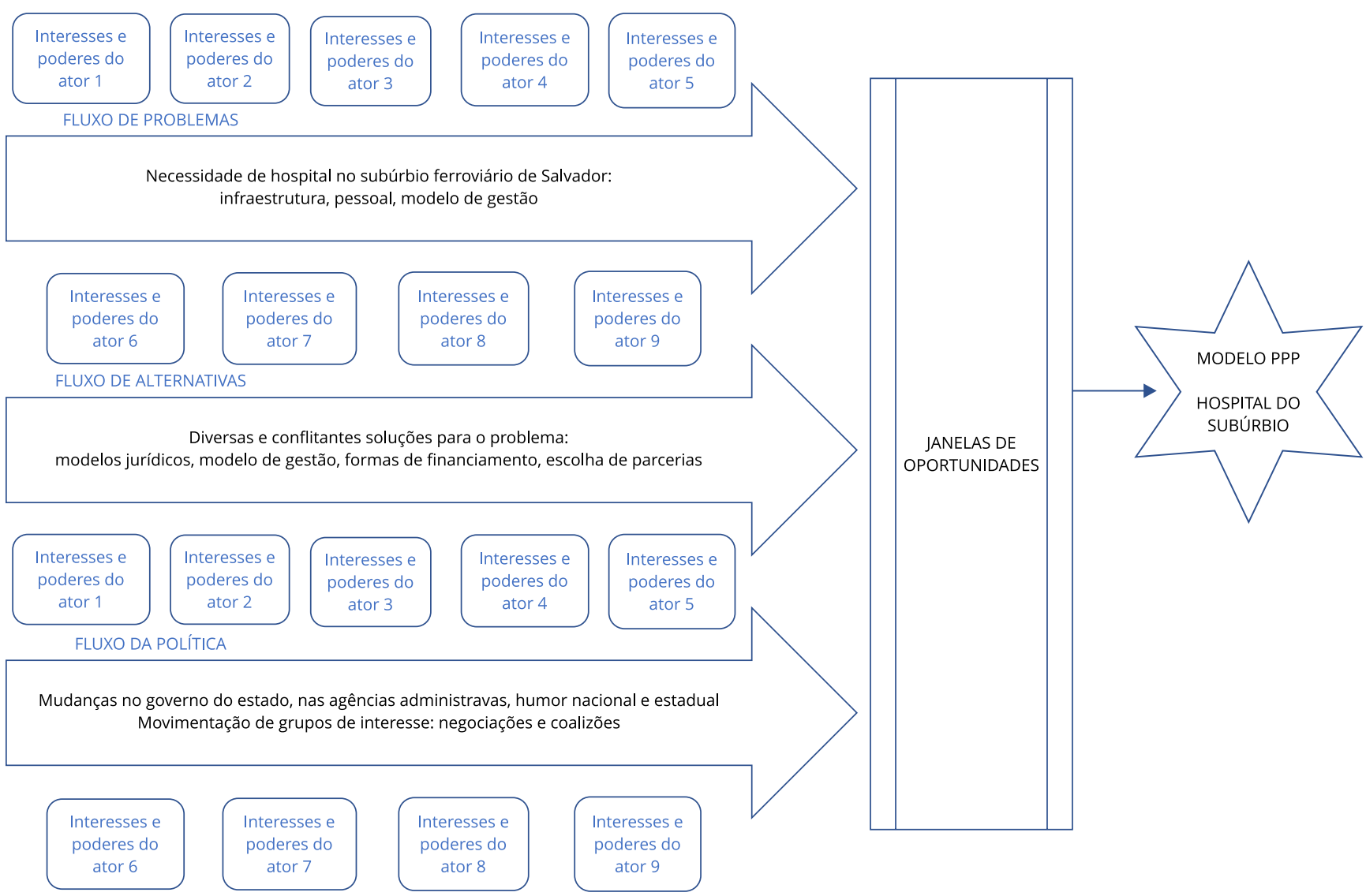

Estadual de Saúde - CES (1), da Corporação Financeira Internacional (IFC)/Banco Mundial (1) e da Promédica Patrimonial (1) 8 .

Além destes atores, outros foram referenciados em atas de reunião da Sesab e nas entrevistas como atores que participaram dos jogos político, econômico e da burocracia em defesa do modelo PPP 8. Foram eles representantes de partidos políticos, membros da Associação Nacional de Hospitais Privados (ANAHP), Banco Nacional de Desenvolvimento Econômico e Social (BNDES), Banco do Nordeste e Desenbahia (Agência de Fomento do Estado da Bahia).

O roteiro semiestruturado para entrevistas continha questões relacionadas aos principais problemas da gestão hospitalar; momento político-institucional da proposta PPP; instituições e atores envolvidos que defenderam ou criticaram a PPP; alternativas de modelos propostas pelos diversos atores; estratégias para favorecer a decisão pelo modelo PPP; e suas vantagens e desvantagens.

Utilizou-se a análise de conteúdo de Bardin 24 para o tratamento das entrevistas; codificação de resultados; categorizações; inferências e informatização da análise das comunicações. As fases da análise foram organizadas em: pré-análise; exploração do material e tratamento dos resultados. A matriz de análise das entrevistas realçou informações como a instituição e função do ator entrevistado, conteúdo da entrevista e seus núcleos de sentido. 


\section{Quadro 1}

Documentos e sites relacionados às parcerias público-privadas (PPP).

\begin{tabular}{|c|c|}
\hline \multicolumn{2}{|r|}{ DECRETO E MEDIDA PROVISÓRIA } \\
\hline Decreto Federal no 5.385/2005 & Institui o Comitê Gestor de Parceria Público-Privada Federal - CGP e dá outras providências \\
\hline Medida Provisória no 727/2016 & $\begin{array}{l}\text { Cria o Programa de Parcerias de Investimentos (PPI) para execução de empreendimentos públicos } \\
\text { de infraestrutura e outras medidas de privatização }\end{array}$ \\
\hline \multicolumn{2}{|l|}{ LEIS } \\
\hline Lei Federal no 11.079/2004 & $\begin{array}{l}\text { Institui normas gerais para licitação e contratação de parceria público-privada no âmbito da } \\
\qquad \text { administração pública e dá outras providências. }\end{array}$ \\
\hline Lei Federal no 9.290/2004 & $\begin{array}{c}\text { Institui o Programa de Parcerias Público-Privadas do Estado da Bahia - PPP Bahia e dá outras } \\
\text { providências }\end{array}$ \\
\hline Lei Federal no 101/2000 & $\begin{array}{l}\text { Estabelece normas de finanças públicas voltadas para a responsabilidade na gestão fiscal e dá } \\
\text { outras providências }\end{array}$ \\
\hline Lei Estadual no 11.477/2009 & $\begin{array}{c}\text { Autoriza a transferência de parcela dos recursos financeiros oriundos do Fundo de Participação dos } \\
\text { Estados (FPE), destinados ao Estado da Bahia, à DESENBAHIA - Agência de Fomento do Estado da } \\
\text { Bahia S.A., para adimplemento das obrigações contraídas pelo Estado da Bahia e entidades da sua } \\
\text { administração indireta em contratos de PPP }\end{array}$ \\
\hline \multicolumn{2}{|r|}{ ATA E RESOLUÇÕES DO CONSELHO GESTOR DE PPP-CGP } \\
\hline Ata de reunião & $\begin{array}{l}\text { Ata de reunião CGP 003/2010: Aprova da proposta de 1a aditivo ao Contrato } \\
\text { do Hospital do Subúrbio }\end{array}$ \\
\hline Resolução & $\begin{array}{l}\text { Resolução CGP no 02/2009: Aprova o Projeto de Modernização Hospitalar do Hospital do Subúrbio, } \\
\text { sua modelagem e minutas de edital e contrato }\end{array}$ \\
\hline Homologação & $\begin{array}{l}\text { Homologação CGP no 002/2009: Aprova preliminarmente o Projeto de Modernização Hospitalar } \\
\text { do Hospital do Subúrbio no que tange ao seu enquadramento legal, bem como a sua inserção no } \\
\text { âmbito do Programa de Parcerias Público-Privadas, conforme dispõe Lei Estadual 9.290/2004 }\end{array}$ \\
\hline \multicolumn{2}{|r|}{ PORTARIAS } \\
\hline Portaria Sefaz-Bahia no 139/2010 & $\begin{array}{l}\text { Define regras para o pagamento das obrigações contraídas pelo estado da Bahia e suas entidades } \\
\text { da Administração Indireta em contratos de PPP, nos termos da Lei Estadual no 11.477/2009 }\end{array}$ \\
\hline \multicolumn{2}{|r|}{ OUTROS DOCUMENTOS } \\
\hline Edital & $\begin{array}{l}\text { Edital de Concessão 008/2009. Concessão administrativa para gestão e operação de unidade } \\
\text { hospitalar do Estado da Bahia - Hospital do Subúrbio, Salvador }\end{array}$ \\
\hline Consulta Pública & Consulta Pública aceca da concessão administrativa da PPP do Hospital do Subúrbio \\
\hline Contrato & $\begin{array}{l}\text { Contrato de Concessão administrativa para gestão e operação de unidade hospitalar do Estado da } \\
\qquad \text { Bahia - Hospital do Subúrbio, Salvador }\end{array}$ \\
\hline Ofícios de Manifestações de Interesse & $\begin{array}{l}\text { - Manifestação de interesse do Banco do Nordeste em financiar o projeto PPP } \\
\text { do Hospital do Subúrbio; } \\
\text { - Manifestação de interesse da IFC/Banco Mundial em financiar o projeto PPP } \\
\text { do Hospital do Subúrbio; } \\
\text { - Manifestação de interesse do BNDES para financiar o projeto PPP do Hospital do Subúrbio }\end{array}$ \\
\hline \multicolumn{2}{|r|}{ SITES RELACIONADOS ÀS PPPS } \\
\hline Secretaria de Fazenda da Bahia & https://www.sefaz.ba.gov.br/administracao/ppp/index.htm \\
\hline Secretaria de Saúde do Estado da Bahia & http://www.saude.ba.gov.br \\
\hline Hospital do Subúrbio & http://www.saude.ba.gov.br/hospital/hospital-do-suburbio/ \\
\hline Radar PPP & https://radarppp.com/ \\
\hline Observatório de PPPs & http://www.pppbrasil.com.br/portal/ \\
\hline
\end{tabular}

BNDES: Banco Nacional de Desenvolvimento Econômico e Social; IFC: Corporação Financeira Internacional.

Fonte: elaboração própria. 
A análise documental foi realizada a partir de uma matriz contendo informações sobre a fonte do documento, conteúdo e identificação de núcleos de sentido que permitiram dialogar com as categorias analíticas .

A pesquisa atendeu às normas do Conselho Nacional de Ética em Pesquisa, seguindo a Resolução CNS no 510/2016, e foi aprovada segundo parecer do Comitê de Ética em Pesquisa do Instituto de Saúde Coletiva da Universidade Federal da Bahia (no 2.799.263/2018). Todos os entrevistados assinaram termo de consentimento livre e esclarecido e são indicados, nesse artigo, como E1, E2, E3 e E4 da Sesab; E5 da Sefaz; E6 da PGE; E7 do CES; E8 da Promédica Patrimonial; e E9 da IFC/Banco Mundial.

\section{Resultados}

Seguindo uma lógica de exposição orientada pelo referencial analítico proposto, apresentamos, inicialmente, a caracterização dos atores institucionais envolvidos no processo decisório em torno da adoção do modelo de gestão do Hospital do Subúrbio, em seguida as alternativas em disputa e a escolha pelo modelo PPP.

Os Quadros 2 e 3 sintetizam as principais posições dos atores, seus papéis nos jogos de poder, argumentos e interesses preponderantes no processo de decisão.

\section{Espaço institucional e atores envolvidos}

A Sesab foi um lugar de grande mobilização da política e espaço onde se desdobraram consensos importantes entre partidos aliados que realizavam a gestão da saúde no estado, especialmente o Partido dos Trabalhadores (PT) e o Partido Comunista do Brasil (PCdoB) 8, apesar da resistência inicial e das críticas deste último referentes à ampliação de modelos de gestão indireta na saúde, neste caso, o Hospital do Subúrbio.

Mesmo com essas divergências internas, foi possível que o governo do estado operacionalizasse, por meio da Sesab, uma de suas propostas da campanha eleitoral, a rápida construção e operação do Hospital do Subúrbio como resposta política às demandas da população. Essa "urgência política", relatada nas entrevistas de E3, E4 da Sesab e E6 da PGE, foi uma das razões apontadas como motivadoras da escolha do modelo PPP. Afinal, entre as alternativas colocadas, apenas o modelo PPP respondia, segundo E6 da PGE, "a necessidade de investimento e a velocidade para inauguração".

A análise do processo decisório em torno da adoção do modelo PPP para gestão do Hospital do Subúrbio levou em conta, em primeiro lugar, a identificação dos atores governamentais e não governamentais envolvidos direta e indiretamente no processo decisório, tratando de mapear suas distintas posições e interesses. Com base na análise das entrevistas, constatou-se que os atores governamentais assumiram a posição, no início do projeto, de "aprendizes" (E3, E4 da Sesab e E6 da PGE), na medida em que o desconhecimento acerca do projeto era comum nos setores do governo. Por conta disso, houve necessidade de assessoria jurídica, (E6 da PGE), por parte da IFC/Banco Mundial, e disponibilização de curso sobre PPP oferecidos a atores governamentais (E3 da Sesab).

Os atores não governamentais IFC/Banco Mundial e BNDES desempenharam papel de apoio ao processo decisório do modelo, segundo entrevista dos atores governamentais e não governamentais (E3, E4 da Sesab, E5 da Sefaz, E8 da Promédica Patrimonial). A IFC/Banco Mundial, interessado em desenvolver PPPs na área de infraestrutura social, foi o responsável pelas pesquisas de avaliação do value for money e contratação de consultores para realizar a modelagem da PPP. O BNDES colaborou na modelagem econômico-financeira 8 .

Finalmente, cabe mencionar que os atores governamentais invisíveis na cena política exerceram papel relevante no processo decisório acerca da escolha do modelo de gestão hospitalar para o Hospital do Subúrbio e atuaram basicamente no momento da implementação da decisão governamental. No caso, trata-se dos funcionários das Sesab e Sefaz, envolvidos no processo de operacionalização da proposta, ou seja, na instituição e inserção de um novo modelo de gestão em serviços de saúde no Estado da Bahia. 


\section{Quadro 2}

Posição dos atores governamentais, seus papéis nos jogos de poder, argumentos e interesses preponderantes.

\begin{tabular}{|c|c|c|}
\hline ATORES GOVERNAMENTAIS & PAPÉIS E PODERES & INTERESSES \\
\hline Sesab & $\begin{array}{l}\text { Participação em todos os jogos de poder. } \\
\text { (poderes político, econômico, macro- } \\
\text {-organizacional, das ciências, da comunicação, } \\
\text { dos valores e pessoal). }\end{array}$ & $\begin{array}{l}\text { Construir, equipar e ofertar serviço de excelência } \\
\text { na saúde, com potencial de replicação para rede. }\end{array}$ \\
\hline \multicolumn{3}{|c|}{$\begin{array}{l}\text { "O Secretário da Saúde é de uma capacidade incrível tanto técnica, mas, sobretudo na capacidade da estratégia, da elaboração, } \\
\text { do discurso, da política" (E4 da Sesab). }\end{array}$} \\
\hline \multicolumn{3}{|c|}{$\begin{array}{l}\text { “...Eu sempre advoguei a ideia de que é possível ter o modelo de gestão direta eficiente. (...) a saúde é um direito do cidadão e dever do Estado, sendo a } \\
\text { obrigação dos gestores do SUS protegê-la da sede de lucro do mercado" (E2 da Sesab). }\end{array}$} \\
\hline \multicolumn{3}{|c|}{$\begin{array}{c}\text { “...Não foi um projeto da Secretaria, foi um projeto de governo, e isso facilitou muito, apesar de ser uma coisa nova. A gente teve, desde o início, desde a } \\
\text { decisão de qual seria o modelo, a gente contou pari passu com a participação direta da PGE, da Sefaz e da Casa Civil” (E1 da Sesab). }\end{array}$} \\
\hline \multicolumn{3}{|c|}{$\begin{array}{l}\text { "A gente queria implementar algo novo... na perspectiva política, da simbologia de fazer algo diferente, que tivesse um valor." } \\
\text { "É um projeto que tem um único contrato. Isso traz muita celeridade para a prestação de serviço e outras vantagens que dizem respeito à transparência } \\
\text { e ao controle" (E4 da Sesab). }\end{array}$} \\
\hline \multicolumn{3}{|c|}{$\begin{array}{l}\text { “... Estado estava no limite prudencial de contratação de Recursos Humanos na área de saúde, que é uma área intensiva e com valores altos. } \\
\text { Com essa preocupação, nós já sabíamos que não iríamos conseguir inaugurar cinco hospitais com modelo tradicional" (E3 da Sesab). }\end{array}$} \\
\hline Sefaz & $\begin{array}{l}\text { Articulação com IFC/Banco Mundial e BNDES, } \\
\text { convênio para estruturação do projeto (poderes } \\
\text { político, econômico, macro-organizacional, das } \\
\text { ciências e da comunicação). }\end{array}$ & $\begin{array}{l}\text { Promover inovações a gestão economia } \\
\text { de escala. }\end{array}$ \\
\hline \multicolumn{3}{|c|}{$\begin{array}{c}\text { "É um projeto público diferenciado". "...Você bota num contrato o que em um hospital por OS, você tem doze contratos. Então, você consegue ter ganhos } \\
\text { de escala" (E5 da Sefaz). }\end{array}$} \\
\hline PGE & $\begin{array}{l}\text { Apoio jurídico ao projeto. (Poderes macro- } \\
\text { organizacional e das ciências) }\end{array}$ & $\begin{array}{l}\text { Aprender sobre o modelo PPP e subsidiar análise } \\
\text { jurídica do modelo. }\end{array}$ \\
\hline
\end{tabular}

BNDES: Banco Nacional de Desenvolvimento Econômico e Social; IFC: Corporação Financeira Internacional; OS: Organizações Sociais; PGE: Procuradoria Geral do Estado; PPP: parceria público-privada; Sefaz: Secretaria de Fazenda do Estado da Bahia; Sesab: Secretaria de Saúde do Estado da Bahia. Fonte: elaboração própria.

\section{Alternativas de modelos de gestão para o Hospital do Subúrbio}

O sistema público de saúde na Bahia dispunha, no momento da pesquisa, de uma variada tradição de experimentação de modelos de gestão hospitalar, pois, além da gestão direta, havia boa parte de hospitais sob gestão de organizações sociais e empresas privadas contratadas. Em 2007, com a mudança de governo e da gestão da Sesab, foi mantida a diversidade de modelos de gestão, como se observa na fala do entrevistado E1 da Sesab:

“...Não tem nenhum modelo que consiga prevalecer. Porque todos têm prós e contras, vantagens e desvantagens, potencialidades e limites que têm que ser levados em consideração. Então, foi por isso que nós optamos em combinar diversas modalidades de gestão hospitalar na rede própria, tentando alcançar o máximo dos objetivos de cada unidade, com o perfil mais adequado" (E1 da Sesab).

Ao se configurar o debate em torno das alternativas para a gestão do Hospital do Subúrbio, apresentaram-se cinco opções: gestão direta, modelo de OS, criação de Fundação Estatal Hospitalar, o modelo de terceirização e o modelo PPP 8 . 
Quadro 3

Posição dos atores não governamentais, seus papéis nos jogos de poder, argumentos e interesses preponderantes.

\begin{tabular}{|c|c|c|}
\hline $\begin{array}{l}\text { ATORES NÃO } \\
\text { GOVERNAMENTAIS }\end{array}$ & PAPÉIS E PODERES & INTERESSES \\
\hline IFC/Banco Mundial & $\begin{array}{l}\text { Expertise do negócio PPP para viabilização do projeto. } \\
\text { (Poder das ciências e econômico) }\end{array}$ & $\begin{array}{l}\text { Desenvolver parcerias na área de "infraestrutura } \\
\text { social", realizar empréstimos. }\end{array}$ \\
\hline \multicolumn{3}{|c|}{$\begin{array}{l}\text { "A contratação da consultoria da IFC se deu porque a Secretaria precisava de uma marca imponente pra dar o peso que a gente precisava" } \\
\text { (E4 da Sesab). }\end{array}$} \\
\hline \multicolumn{3}{|c|}{$\begin{array}{l}\text { "(...) Muito comum a gente ser chamado ou identificar alguma situação viável e ir conhecer o prefeito ou governador. Eu vivia viajando atrás de } \\
\text { oportunidades de fazer projetos, não só no setor de saúde, mas projetos de PPPs inovadores" (E9 da IFC/Banco Mundial). }\end{array}$} \\
\hline \multicolumn{3}{|c|}{$\begin{array}{c}\text { "Todo processo de construção da modelagem foi feito com a IFC, que trabalhou com os técnicos da Secretaria de Saúde, para a construção dos } \\
\text { indicadores econômicos financeiros e assistenciais, para daí construir metas, precificação e, com isso, resultar no contrato. Eles receberam recursos em } \\
\text { valor por essa consultoria" (E2 da Sesab). }\end{array}$} \\
\hline CES/Bahia & $\begin{array}{l}\text { Afirma não ter exercido seu papel de deliberação no } \\
\text { processo de decisão (Poder político) }\end{array}$ & Debater, deliberar, acompanhar e avaliar a PPP \\
\hline \multicolumn{3}{|c|}{$\begin{array}{l}\text { "Eu não participo da decisão e nem tenho acesso a uma análise. Essa análise é uma cobrança que o Conselho deve fazer"; “(...) a expectativa é de não } \\
\text { ter mais nenhuma modalidade de gestão, a não ser administração direta” (E7 do CES). }\end{array}$} \\
\hline \multicolumn{3}{|c|}{ “(...) O Conselho questionou, mas não comprou nenhuma briga muito forte em relação a isso, não” (E1 da Sesab). } \\
\hline Promédica Patrimonial & $\begin{array}{l}\text { Concorrente na licitação e hoje gestora do Hospital do } \\
\text { Subúrbio (Poder Econômico) }\end{array}$ & $\begin{array}{l}\text { Ganhar experiência no negócio PPP; reduzir } \\
\text { custos com fornecedores; lucrar com a taxa de } \\
\text { retorno, pela gestão do Hospital do Subúrbio }\end{array}$ \\
\hline \multicolumn{3}{|c|}{$\begin{array}{l}\text { "(...) O grande ativo que ficou dessa operação foi a experiência adquirida. Tem outros ganhos em paralelo, como volume para negociar com os } \\
\text { fornecedores. (...) o grande mercado da saúde está no público, e não no privado, em termos quantitativos" (E8 da Promédica). }\end{array}$} \\
\hline
\end{tabular}

BNDES: Banco Nacional de Desenvolvimento Econômico e Social; CES: Conselho Estadual de Saúde; IFC: Corporação Financeira Internacional; OS: Organizações Sociais; PGE: Procuradoria Geral do Estado; PPP: parceria público-privada; Sefaz: Secretaria de Fazenda do Estado da Bahia; Sesab: Secretaria de Saúde do Estado da Bahia.

Fonte: elaboração própria.

A alternativa "gestão direta" era defendida tanto pelo CES, que, segundo seu representante, (E7 do CES) tinha: "a expectativa de não ter mais nenhum tipo de modalidade de gestão, a não ser administração direta”, quanto por setores da própria Sesab (E2 da Sesab), que consideravam o modelo de gestão direta como capaz de permitir a implementação de um "modelo democrático de gestão", com pactuação da produtividade junto aos trabalhadores e qualificação do serviço público:

“...Colocar na gestão de pessoas que têm capacidade de gestão e ter, dentro da gestão direta, um modelo democrático. É possível fazer um plano diretor de um hospital de gestão direta? Sim. É possível envolver os trabalhadores no cumprimento dessas metas, a partir da capacidade instalada, do que existe de recursos. Ver metas realistas e pactuar com trabalhadores para atendimento da produtividade coletiva, com compromisso coletivo" (E2 da Sesab).

Por outro lado, o entrevistado E1 da Sesab trouxe para o debate os limites jurídicos da gestão direta, ao comentar que: "Se um equipamento quebrar e você não resolver o problema, isso não dá processo pro gestor. Pode ficar o tomógrafo parado três meses, mas, se ele chamar alguém pra consertar e pagar por indenização, ele pode ser processado".

O modelo OS, por sua vez, foi aventado como possível para o Hospital do Subúrbio, uma vez que já possuía base legal, tendo sido o modelo mais discutido como alternativa para a gestão do Hospital do Subúrbio. Muitos entrevistados (E1, E2, E3, E4 da Sesab, E6 da PGE) comentaram que se debruçaram na análise das limitações desse modelo para justificar por que não o escolheram, apontando, entres outros motivos, a impossibilidade de realizarem investimentos em equipamentos necessários à 
abertura do hospital, pequeno número de OS no Estado e inexistência de expertise para fazer gestão de um hospital com o perfil do Subúrbio, ausência de compartilhamento de risco entre entes público e privado previstos na lei brasileira de PPP 25 , além das questões relativas à idoneidade de algumas OS.

Já a Fundação Hospitalar foi descrita como um modelo novo e questionável e, por isso, teria sido "uma alternativa descartada" (E1 da Sesab).

Para o ator governamental E6 da PGE, que comparou os três modelos: Fundação Estatal, OS e as PPPs, havia nas fundações problemas de riscos jurídicos e desconhecimento se o modelo integraria o orçamento fiscal. Segundo ele, o modelo PPP já tinha sido organizado na legislação e tinha alguma experiência no país, além de atender a necessidade de investimento e a velocidade requerida para inauguração ${ }^{8}$.

\section{A escolha e incorporação do modelo PPP}

$\mathrm{Na}$ análise do processo político de incorporação do novo modelo para a gestão hospitalar, cabe destacar, em primeiro lugar, que as mudanças no âmbito do governo estadual e, também, na gestão da Sesab foram elementos fulcrais para a entrada da PPP na agenda governamental da Bahia. O processo de decisão nos âmbitos governamental e não governamental foi permeado pela movimentação dos grupos de pressão ligados as secretarias do governo, sindicatos, partidos políticos, instituições financeiras internacionais, bancos e controle social, este último em menor grau.

No caso em estudo, a escolha pela PPP baseou-se em argumentos como: reconhecimento da agilidade na equipagem e manutenção da unidade, o que permitiria sua breve inauguração; transparência no processo licitatório; estabelecimento de contrato único para gestão de vários serviços, o que deveria trazer transparência, marco regulatório favorável; agilidade na prestação de contas e controle para o gestor; além da definição de desembolsos mensais pelo gestor público, entre outros motivos elencados pelos defensores nas entrevistas (E1, E3 e E4 da Sesab, E6 da PGE).

As razões da escolha da PPP apontadas pelo E1 da Sesab demonstram que a existência do modelo, aplicado em outros setores no estado, também foi um facilitador da decisão, evidenciando que, neste processo, ocorreu o que Kingdon 11 denomina de "trasbordamento", ou seja, o fato de os políticos perceberem maior facilidade na execução de uma política similar a outra que já obteve sucesso.

“...Apesar de ser a primeira na saúde, o Estado já tinha um acúmulo com a PPP do emissário submarino, por parte da Secretaria de Fazenda e Procuradoria Jurídica. Existia até o modelo de contrapartidas e uma consultoria do Banco Mundial que trabalhava com o Estado nesse âmbito. Então terminou ganhando essa possibilidade" (E1 da Sesab).

Outro elemento fundamental e requisito legal para a escolha do modelo PPP pela gestão foi a comprovação do value for money 15 ou vantagens socioeconômicas conforme a Lei no 11.079/2004, ou seja, após uma análise de custos comparativos, o modelo tem que se mostrar, no jogo econômico, ser menos dispendioso que os demais 25. Neste caso, o value for money do contrato da PPP foi apontado por um dos atores governamentais como elemento que apoiou a tomada de decisão:

“...O HGE era o hospital-irmão pelo porte, tipo de paciente, apesar de o Hospital do Subúrbio ter pacientes de emergência clínica. O paradigma seria o HGE, porque o estado não tinha sistema de apropriação de custo, $e$ não sei se tem até hoje, que realmente mostrasse o value for money, que englobasse uma quantidade maior de unidades. Então a gente comparou os modelos de vantajosidade usando o HGE como elemento de comparação" (E3 da Sesab).

Já o debate do custo-efetividade foi trazido pelo ator não governamental IFC/Banco Mundial, associando-o à qualidade e responsabilidade do parceiro privado que assume o hospital:

$\mathrm{O}$ custo financeiro tende a ser mais alto do que o custo normal do ente operar na rede pública. $\mathrm{Na}$ hora de fazer uma PPP, vai ter que puxar os indicadores de qualidade para cima, e aí começa a envolver outro nível de parceiro privado, que em regra tem certificação pelo menos via ONA. Esse parceiro custa mais caro (E9 da IFC/Banco Mundial).

As vantagens socioeconômicas apontadas (por E1, E3 e E4 da Sesab, E5 da Sefaz, E6 da PGE e E8 da Promédica) como motivadoras da escolha do modelo relacionam-se, ainda, ao estabelecimento, no contrato 11,26, de metas, indicadores de eficiência, agilidade dos serviços prestados e obrigatoriedade da acreditação hospitalar. 
A competição e inovação requeridas para modelos de gestão em saúde, no bojo de um sistema capitalista, são apontadas como característica importante a ser considerada para escolha dos modelos. Segundo um dos atores governamentais que defendem esse ponto de vista, um "modelo híbrido" seria capaz de melhorar os custos e prestar bons serviços à população:

“...Esse modelo híbrido faz sentido porque coloca parte do que é manejado muito bem pelo sistema capitalista de lucratividade, as empresas da área de construção civil e de manutenção, tem muitas e elas são espertas, fazem inovação rapidamente. Então, se há competição entre eles mesmos, entre como é que eu consigo melhorar meu custo de capital para conseguir fazer esse serviço melhor para o Estado, esse nível de competitividade nesse espaço é interessante" (E6 da PGE).

Os defensores mais aguerridos do modelo dentro da Sesab (E1, E3 e E4) apresentaram argumentos relativos às limitações da gestão direta na contratação de pessoal, marcadamente por conta da Lei de Responsabilidade Fiscal, e apontaram os limites das organizações sociais no que se refere a suas restrições para investimento em compra de equipamentos e manutenção desses. Esses mesmos entrevistados realçaram o aprendizado institucional e busca por inovação, performance, excelência, modernização do sistema de saúde e qualidade, argumentos que são coadunados com achados na literatura 10,11,12,13,14,15,19 sobre as PPPs. A valorização da inovação também aparece na fala do entrevistado E6 da PGE, que considera que, além dos modelos já experimentados no estado, "há possibilidade de outros novos desenhos serem aplicados no campo da gestão hospitalar".

A questão da contratação de pessoal, entretanto, foi um aspecto polêmico que permeou todo o processo, especialmente pela posição dos sindicatos de trabalhadores de saúde que apontava o fato de que a adoção da PPP implicaria na contratação dos profissionais por uma empresa privada. Desse modo, embora os sindicatos de trabalhadores de saúde reconhecessem a necessidade de novo hospital em uma região desassistida como o Subúrbio Ferroviário, ofereceram certa "resistência" ou "oposição" à adoção do modelo PPP 8.

Nesse ponto, evidenciou-se a maestria do empreendedor da política que, estando à frente de uma jogada conflituosa, desempenhou um papel fundamental na formação de opinião favorável ao modelo PPP. As entrevistas de E3 e E4 da Sesab destacaram que o empreendedor soube utilizar suas variadas habilidades política, técnica, comunicacional, entre outras, para contornar uma possível oposição, garantindo a aliança do PCdoB, partido que dividia a gestão da Sesab com o PT, e seu apoio estratégico para negociar com seus afiliados, pertencentes a esses sindicatos.

Apesar disso, a discussão em relação ao modelo de gestão do trabalho das PPPs não foi um ponto de convergência, sendo destacado como vantajoso socioeconomicamente por um grupo de atores governamentais e não governamentais (E1, E3, E4 da Sesab, E6 da PGE e E9 da IFC/Banco Mundial) e para o outro (E2 da Sesab e E7 do CES) como se constituindo como "desvio da função estatal".

\section{Discussão: jogos de poder na decisão pelo modelo PPP}

O processo político em torno da decisão do modelo PPP para gestão do Hospital do Subúrbio contou com intensa participação de atores governamentais e não governamentais, e foi atravessado por diferentes jogos de poder, especialmente o político, macro-organizacional, econômico, das ciências, comunicação e jogo dos valores. Esses jogos se influenciaram reciprocamente de forma decisiva, tanto no que diz respeito aos aspectos que provocaram conflitos quanto na construção da cooperação necessária entre os diversos atores.

Essa interação entre os atores foi destacada nas entrevistas como marcado pelo jogo das ciências, caracterizado pela influência exercida no processo pela expertise da IFC/Banco Mundial no negócio PPP. Os consultores da IFC/Banco Mundial atuaram de forma integrada a técnicos, juristas e assessores da Sesab, Sefaz e PGE na modelagem do projeto PPP, demarcando seu potencial de influenciador na decisão, imprimindo sua marca no modelo e nos aspectos jurídicos e técnicos. Inclusive, a entrevista do seu representante, E9 da IFC/Banco Mundial, anunciou o objetivo de desenvolver projetos na área de infraestrutura social, vislumbrado um potencial de se fazer PPP no setor de saúde no Brasil.

A análise do jogo das ciências também permitiu perscrutar a influência dos experts da IFC/Banco Mundial e BNDES na própria constituição do interesse de atores, pois, como a PPP precisa, por lei, apresentar vantagens socioeconômicas em relação a outros modelos, cabe ao gestor eleger esse mode- 
lo apenas nos casos em que se apresente como mais vantajoso para a administração pública. E isso depende dos estudos prévios que foram realizados pela IFC/Banco Mundial.

Ao mesmo tempo, esses atores também atuaram no jogo econômico disputando interesses inerentes ao setor privado ao qual pertencem. Um dos atores não governamentais, E8 da Promédica, afirmou sua compreensão da saúde enquanto mercado por meio das expressões: "o grande mercado da saúde está no setor público"; "ganho de volume pra negociar com fornecedores" e "obter experiência de gestão no negócio PPP”. Assim, entende a dimensão econômica da parceria como algo positivo, no sentido de que há previsão do que investir financeiramente, informações acerca da quantidade dos serviços a serem prestados e sobre a taxa de retorno financeiro da PPP, ou seja, o lucro advindo da parceria.

Em desacordo com os interesses de lucro dos atores do setor privado envolvidos, o ator governamental E2 da Sesab se contrapunha ao modelo argumentando que no sistema público de saúde há poucos recursos e, portanto, não faria sentido aderir a nenhum modelo que tivesse lucro como princípio.

A análise do jogo dos valores expresso pelas crenças e ideologias a respeito da relação público-privada dos atores envolvidos permite revelar a existência ou não de consciência ética com a qualidade dos serviços; inovação e criatividade; compromissos entre empregado/instituição. Nesse sentido, no interior da Sesab e também na Sefaz, os atores governamentais E1, E3 e E4 da Sesab e E5 da Sefaz adjetivavam o modelo PPP com expressões que se referiam a "algo inovador", "simbólico”, "capaz de garantir qualidade" e "universalizar acesso" 8.

O interesse de "inovar" associado a uma urgência na entrega de uma unidade hospitalar, segundo o ator governamental E3 da Sesab, fez que o debate se iniciasse com participação restrita a alguns setores da Sesab e dentro do governo. A ampliação das discussões ocorreu pelos ritos requeridos na Lei no 11.079/2004 25, que prevê consulta pública, audiência pública e disponibilização em site do governo.

Notaram-se também, no jogo dos valores, posicionamentos ideológicos diferentes acerca do uso de modelos de gestão privados, incluindo a PPP, advindos da E2 da Sesab e, também, do ator não governamental E7 do CES. Esse último ator afirmou não ter exercido seu poder no jogo político, por não ter participado com "papel de deliberação no processo de decisão" acerca do modelo.

Preocupações apontadas por E2 da Sesab e E7 do CES nas entrevistas também são abordadas na literatura no que tange aos questionamentos da capacidade de o parceiro público: elaborar projetos de PPP que atendam a seus interesses; negociar contratos; garantir uma efetiva distribuição de risco com o privado; e acompanhar o desempenho da PPP referente à qualidade dos serviços prestados $11,13,15,16,17,19$. Nesse sentido, outros estudos 10,18 sugerem que as razões da escolha da PPP, pelo mundo e no campo da saúde, sejam aprofundadas para o entendimento da ampliação desse modelo.

Por fim, cabe destacar a análise do jogo da comunicação, capaz de apoiar todos os demais jogos no plano do entendimento entre jogadores. Por meio dele, o policy entrepreneurs 22 - empreendedor da política - desempenha papel fundamental unindo soluções a problemas, propostas a momentos políticos e eventos políticos a problemas. Utiliza transparência, opacidade e controle da informação na relação com os outros atores.

O reconhecimento do empreendedor do projeto foi uma unanimidade nas entrevistas (E2, E3, E4 da Sesab; E5 da Sefaz; E6 da PGE; E7 do CES; E8 da Promédica; e E9 da IFC/Banco Mundial) que caracterizaram o Secretário de Saúde da época, apoiado pelo governador, como o "decisor do modelo" com múltiplas competências em diferentes jogos (político, macro-organizacional, das ciências, valores, pessoal, comunicação, burocracia), desempenhando papel fundamental na formação de opinião favorável ao modelo.

Destaca-se também que a escolha da alternativa PPP para a gestão do Hospital do Subúrbio, diante de modelos como OS e Fundação, encontrou amparo na literatura sobre PPP 13,14,15,16,17,18,19, cujos estudos argumentavam sobre suas vantagens, tais como a divisão de riscos; análise prévia de custo-benefício e viabilidade técnica do projeto; governança e autoridade compartilhada entre público e privado.

Como o jogo social acerca da decisão do modelo PPP envolveu vários jogos paralelos, simultâneos e imbricados, cada um com lógica própria de competição, tempo e desenvolvimento diferentes, ficou claro que os interesses desses atores estratégicos foram negociados e equacionados para que o modelo PPP fosse o escolhido entre outras alternativas. 


\section{Considerações finais}

Diante dos problemas da atenção hospitalar que deram origem à necessidade de construção e operação do Hospital do Subúrbio, atores governamentais e não governamentais apresentaram suas alternativas de modelos de gestão e disputaram posições no processo político que envolveu a tomada de decisão, acionando vários jogos de poder nos quais interesses, argumentos e estratégias de convencimento entraram na trama da negociação.

O estudo evidencia a pertinência da associação da teoria do jogo social com a terceira corrente de Kingdon, denominado o processo político em torno das alternativas, que auxiliou no mapeamento do campo de forças, identificação dos atores visíveis e invisíveis que tiveram destaque no processo decisório, além de explicitar quais interesses defendiam e/ou disputavam para que se compreendessem as razões e a forma como o modelo PPP foi a alternativa escolhida.

As evidências produzidas por essa pesquisa lançam novas luzes sobre a problemática das reformas gerenciais, especificamente no que tange à gestão hospitalar. A PPP é um tema instigante de estudo, pois traz em sua órbita interesses políticos, econômicos e ideológicos que ultrapassam fronteiras e envolvem grandes corporações financeiras. Ao mesmo tempo, a nível local, por meio da PPP busca-se resolver questões cruciais para expansão do acesso a serviços de saúde e da qualidade de atendimento no SUS.

Apesar da análise minuciosa das entrevistas, documentos, suporte teórico, a partir do quadro analítico e revisão de literatura, vale ressaltar alguns limites do estudo, como a impossibilidade de aprofundar a análise do value for money, pois demandaria uma expertise não dominada pelas autoras. Da mesma forma que as explicações dos determinantes estruturais das posições adotadas, pelos diversos autores, não foram contemplados exaustivamente.

Apesar disso, considera-se que os resultados deste estudo podem subsidiar a elaboração de alternativas e estratégias de mudança que contemplem a melhoria do desempenho do Estado e das organizações públicas de saúde. A identificação e análise das debilidades das propostas incluídas na agenda indicam a necessidade de aperfeiçoamento e construção de consenso em torno das alternativas de gestão de unidades complexas, como é o caso dos hospitais públicos.

No entanto esses limites não comprometem o objetivo de analisar os processos de tomada de decisão acerca do modelo PPP para gestão hospitalar e avança no diálogo entre o referencial do ciclo da política pública e outras perspectivas teóricas que contribuíram para o enriquecimento do modelo de análise. Da mesma forma, as evidencias produzidas são compreendidas como horizontes para novos estudos no campo da saúde coletiva, pois convida a realização de novas pesquisas relacionadas ao impacto das parcerias no desempenho clínico, no cumprimento dos princípios e das diretrizes do SUS, entre outras.

Também convoca a realização de estudos que se debrucem sobre a transparência na avaliação do value for money e na análise de dados econômicos das PPPs, buscando esclarecer sua eventual relação com a financeirização da saúde, particularmente no que tange à lucratividade das empresas privadas envolvidas nas parcerias.

Assim, o aprofundamento do monitoramento da influência de grupos internacionais interessados na exploração de PPPs na saúde, no Brasil e no mundo, se mostra necessário, tendo em vista os poderes que esses dispõem nos jogos político, econômico e da ciência. Esses imbricados aos jogos da burocracia e da comunicação foram potencializadores da decisão desse modelo para gestão hospitalar no SUS da Bahia. 


\section{Colaboradores}

L. R. Andrade contribuiu na concepção e delineamento do estudo, na análise e interpretação dos dados do trabalho, na elaboração de versões do artigo e revisão crítica, na aprovação final da versão a ser publicada e concordância em ser responsável por todos os aspectos do trabalho. I. C. M. Pinto contribuiu na concepção e delineamento do estudo, na análise e interpretação dos dados do trabalho, revisão crítica do conteúdo intelectual, na aprovação final da versão a ser publicada, na concordância em ser responsável por todos os aspectos do trabalho.

\section{Informações adicionais}

ORCID: Laíse Rezende de Andrade (0000-00021149-7636); Isabela Cardoso de Matos Pinto (00000002-1636-2909).

\section{Agradecimentos}

Agradecemos à professora Carmen Teixeira, docente do Bacharelado Interdisciplinar em Saúde, do Mestrado do Programa de Estudos Interdisciplinares sobre Universidade, no Instituto de Humanidades, Artes e Ciências e do Programa de Pós-graduação do Instituto de Saúde Coletiva da Universidade Federal da Bahia (ISC-UFBA), e pesquisadora do Observatório de Análise Política em Saúde (ISC-UFBA/CNPq) pelo apoio na revisão final do artigo.

\section{Referências}

1. Souza DO. Financeirização, fundo público e os limites à universalidade da saúde. Saúde Debate 2019; 43(spe 5):71-81.

2. Funcia FR. Subfinanciamento e orçamento federal do SUS: referências preliminares para a alocação adicional de recursos. Ciênc Saúde Colet 2019; 24:4405-14.

3. Souza DO. Under the leadership of the World Bank: challenges in, and perspectives of, the SUS counter-reform. Physis (Rio J.) 2020; 30:e300101.

4. Campos GW. SUS: o que e como fazer? Ciênc Saúde Colet 2018; 23:1707-14.

5. Departamento de Informática do SUS. Cadastro Nacional de Estabelecimentos de Saúde (CNES). Leitos de internação hospitalar. http://tabnet.datasus.gov.br/cgi/tabcgi. exe?cnes/cnv/leiintbr.def (acessado em 01/ Abr/2019).

6. Mota E. Norte e Nordeste têm defasagem de leitos de UTI em relação a outras regiões do país. https://coronavirus.ufba.br/norte-e-nor deste-tem-defasagem-de-leitos-de-uti-em-re lacao-outras-regioes-do-pais (acessado em 28/ Jun/2021).

7. Pinto I, Silva L, Baptista T. Ciclo de política pública de saúde: problematização, construção da agenda, institucionalização, formulação, implementação e avaliação. In: Paim J, Almeida-Filho N, organizadores. Saúde coletiva: teoria e prática. Rio de Janeiro: MedBook; 2014. p. 69-81.

8. Andrade LR. A escolha de parceria público - privada para gestão hospitalar na Bahia: atores, interesses e estratégias [Tese de Doutorado]. Salvador: Universidade Federal da Bahia; 2019.

9. Andrade L, Pinto I. Parcerias Público-Privadas na gestão hospitalar: expressão no Brasil e no mundo. In: Santos T, Pinto I, organizadores. Gestão hospitalar no SUS. Salvador: EdUFBA; 2021.

10. Bachelet V. Concesiones hospitalarias en Chile: dónde estamos y hacia dónde vamos. Medwave 2014; 14:e6039.

11. Carrera MB. Parceria Público-Privada (PPP): análise do mérito de projetos do setor saúde no Brasil [Tese de Doutorado]. São Paulo: Escola de Administração de Empresas de São Paulo, Fundação Getúlio Vargas; 2014.

12. Cruz NF, Marques RC. Accountability and governance in local public services: the particular case of mixed companies. Innovar 2011; 21:41-54.

13. La Forgia GM, Harding A. Public-Private Partnerships and public hospital performance in São Paulo, Brazil. Health Aff (Millwood) 2009; 28:1114-26.

14. Fernandez RN, Hillbrecht R, Carrarro A. Desenho contratual e parcerias público-privadas para hospitais, 2014. http://www.anpec.org. br/encontro/2014/submissao/files_I.pdf (acessado em 25/Out/2016). 
15. Darvish H, Zou PX, Loosemore M, Zhang G. Risk management, public interests and value for money in PPP projects: literature review and case studies. In: The CRIOCM International Symposium, 2006. http://www.irbnet. de/daten/iconda/CIB5826.pdf (acessado em 03/Fev/2020).

16. Barbosa AP, Malik AM. Desafios na organização de parcerias público-privadas em saúde no Brasil: análise de projetos estruturados entre janeiro de 2010 e março de 2014. Revista de Administração Pública 2015; 49:1143-65.

17. Cabral S, Fernandes AS, Ribeiro DB. Os papéis dos stakeholders na implementação das parcerias público-privadas no Estado da Bahia. Cadernos EBAPE.BR 2016; 14:335-29.

18. Civitillo R, Rossi M. Public private partnerships: a general overview in Italy. Procedia - Social and Behavioral Sciences 2014; 109:140-9.

19. McIntosh N, Grabowski A, Jack B. A publicprivate partnership improves clinical performance in a hospital network in Lesotho. Health Aff (Millwood) 2015; 34:954-62.
20. Yin R. Estudo de caso: planejamento e métodos. Porto Alegre: Bookman; 2005.

21. Matus C. Teoria do jogo social. São Paulo: Fundap; 2005

22. Kingdon JW. Agendas, alternatives and public policies. 2nd Ed. Ann Arbor: University of Michigan Press; 2003.

23. Handcock MS, Gile KJ. On the concept of snowball sampling. Sociol Methodol 2011; 41:367-71.

24. Bardin L. Análise de conteúdo. Lisboa: Edições 70; 2009.

25. Brasil. Lei no 11.079 , de 30 de dezembro de 2004. Institui normas gerais para licitação e contratação de parcerias público-privadas no âmbito da administração pública. Diário Oficial da União 2004; $31 \mathrm{dez}$.

26. Secretaria da Saúde do Estado da Bahia. Hospital do Subúrbio. Contrato de concessão administrativa para gestão e operação de unidade hospitalar do Estado da Bahia. Salvador: Secretaria da Saúde do Estado da Bahia; 2009. 


\section{Abstract}

The process of building Brazil's Unified Health System has always been a space of dispute between the political forces that defend greater private sector participation in patient care and administration of services and those who defend strengthening public administration. In the context of underfinancing of the Brazilian Unified National Health System (SUS), associated with the restrictions imposed by the so-called Fiscal Responsibility Law, new management models have been adopted in hospital administration, including public-private partnerships (PPPs). Considering the relevance of investigating decision-making processes pertaining to the adoption of these models by State Health Departments, this study aims to analyze the decision-making processes and incorporation of this hospital administration model in the State of Bahia, Brazil, the first administrative concession in Brazil's health sector. This is a case study in which the theoretical reference was Social Game Theory elaborated by Carlos Matus, linked to the Public Policy Cycle analytical model. The data were produced with document research and semi-structured interviews with key informants who participated in the pre-decision and decisionmaking stages of the PPP model. The article presents the political game involved in the choice of this alternative among other hospital administration models, besides debating the models' advantages and disadvantages according to the key actors and concludes that determinants (not only financial, but also political and ideological) marked the decision-making process for the PPP model in Bahia, in which the driving factor and source of consultancy was the International Finance Corporation, an arm of the World Bank.

Public-Private Sector Partnership; Hospital Administration; Public Policy; Unified Health System

\section{Resumen}

El proceso de construcción del Sistema Único de Salud ha sido, desde el comienzo, un espacio de disputa entre las fuerzas politicas que defienden la ampliación de la participación del sector privado en la asistencia y gestión de los servicios, y los defensores del fortalecimiento de la gestión pública. En el contexto de la subfinanciación del SUS, asociado a las restricciones impuestas por la Ley de responsabilidad fiscal, se han adoptado nuevos modelos de gestión, especialmente en el área de gestión hospitalaria, como por ejemplo la colaboración público-privada (PPP por sus siglas en portugués). Considerando la relevancia de investigar los procesos de decisión, relativos a la adopción de esos modelos por parte de las Secretarías Estatales de Salud, este trabajo tiene como objetivo analizar los procesos de toma de decisión e incorporación de este modelo de gestión hospitalaria en el Estado de Bahía, Brasil, primera concesión administrativa en el sector de salud de Brasil. Se trata de un estudio de caso, que tomó como marco de referencia teórico la Teoría de Juego Social, elaborada por Carlos Matus, coordinada con el modelo analítico del Ciclo de Politicas Públicas. Los datos fueron producidos a partir de una investigación documental y entrevistas semiestructuradas con informantes-clave que participaron en los momentos de pre-decisión y decisión acerca del modelo PPP. El artículo presenta el juego político en torno de la elección de esa alternativa entre otros modelos para gestión hospitalaria, además de debatir ventajas y desventajas de los modelos, según actoresclaves entrevistados, y concluye que determinantes no solo financieros, sino políticos e ideológicos marcaron el proceso de decisión del modelo PPP en Bahía, que tuvo como fomentador y consultor al brazo derecho del Banco Mundial, la Corporación Financiera Internacional.

Asociación entre el Sector Público-Privado; Administración Hospitalaria; Política Pública; Sistema Único de Salud
Recebido em 21/Jan/2021

Versão final reapresentada em 08/Ago/2021

Aprovado em 13/Ago/2021 